\title{
(2) OPEN ACCESS \\ Giant cell-rich solitary fibrous tumour of the lacrimal gland with prominent angiomatoid cystic changes and an underlying NAB2ex3-STAT6ex18 fusion
}

\author{
Khaled A Alsaadi, ${ }^{1}$ Manar Alwohaib, ${ }^{1}$ Karen Pinto, ${ }^{2}$ Rola H Ali (i) ${ }^{3,4}$
}

\begin{abstract}
${ }^{1}$ Al Bahar Eye Center, Ibn Sina Hospital, Shuwaikh, Kuwait ${ }^{2}$ Department of Pathology, Kuwait Cancer Control Center, Shuwaikh, Kuwait ${ }^{3}$ Department of Pathology, Faculty of Medicine, Kuwait University, Jabriyah, Kuwait ${ }^{4}$ Cytogenetics Laboratory, Kuwait Cancer Control Center, Shuwaikh, Kuwait
\end{abstract}

Correspondence to

Dr Rola H Ali;

rola.ali@ku.edu.kw

Accepted 6 January 2022

Check for updates

(c) BMJ Publishing Group Limited 2022. Re-use permitted under CC BY-NC. No commercial re-use. See rights and permissions. Published by BMJ.

To cite: Alsaadi $K A$,

Alwohaib M, Pinto $\mathrm{K}$

et al. BMJ Case Rep

2022:15:e247141

doi:10.1136/bcr-2021-

247141

\section{SUMMARY}

Giant cell-rich solitary fibrous tumour (GCR-SFT) is a rare variant of SFT with a predilection for the orbital region. Despite its hypervascularity, extensive angiomatoid cystic changes are unusual in GCR-SFT and may pose a diagnostic challenge. A 47-year-old man presented with a right eye proptosis and a protruding tumour of several years' duration with recently accelerated tumour growth. MRI revealed a cystic-solid heterogeneous mass arising from the lacrimal gland and displacing the globe. A subtotal excision of the mass was performed due to unanticipated hypervascularity and intraoperative bleeding. Pathologically, a vascular neoplasm was initially suspected. The diagnosis of GCR-SFT was made following careful evaluation and demonstration of CD34 and STAT6 expression. Molecular studies revealed a pathognomonic but rare NAB2ex3-STAT6ex18 fusion variant as well as a TP53 mutation suggestive of aggressive phenotype. The patient had a complete resolution of the proptosis but the clinical picture remains guarded due to incomplete resection.

\section{BACKGROUND}

Solitary fibrous tumour (SFT) is an uncommon neoplasm of mesenchymal fibroblastic origin known to arise at numerous anatomical locations, with the pleura being one of the most common. Orbital involvement has been increasingly recognised since their first description in $1994,{ }^{12}$ probably due to increased awareness of this entity, refined diagnostic histological criteria ${ }^{3}$ and advent of STAT6 immunohistochemistry as a specific marker for SFT and a surrogate for the pathognomonic NAB2STAT6 gene fusion. ${ }^{4}$ Accurate diagnosis is largely dependent on having a high index of suspicion and appreciation of the protean radiological and pathological features. While most SFTs are slow-growing indolent tumours, they are notorious for their unpredictable clinical behaviour irrespective of the histology. Complete surgical resection is required to reduce the risk of local recurrences and potential malignant transformation.

Giant cell-rich solitary fibrous tumour (GCRSFT), formerly known as giant cell angiofibroma, was first described in 1995 as a distinctive orbital tumour in adults. ${ }^{5}$ Subsequently, reports of GCRSFTs at extraorbital locations started to emerge. ${ }^{6}$ Currently, GCR-SFT is classified as a histological variant of SFT based on the overlapping clinicopathological, immunohistochemical and genetic features. ${ }^{3}$ GCR-SFTs are known to be richly vascularised, although extensive cystically dilated angiomatoid spaces are unusual. Herein, we report an orbital GCR-SFT displaying such extensive angiomatoid changes reminiscent of a vascular tumour, posing a diagnostic challenge. Awareness of these features is important among radiologists, ophthalmologists and pathologists for optimal preoperative diagnosis and surgical planning.

\section{CASE PRESENTATION}

A 47-year-old man presented with progressive painless protrusion of the right eye for several years associated with blurred vision (figure 1A). Physical examination showed right eye proptosis measuring $30 \mathrm{~mm}$ on exophthalmometry (in comparison to $21 \mathrm{~mm}$ on the left side). This was accompanied by significant conjunctival chemosis, corneal exposure and dryness, and diffuse punctate erosions. Additionally, a congested protruding swelling was visible laterally, which seemed to be the cause of the globe displacement. Extraocular movements were restricted in all gaze directions. Visual acuity was $20 / 400$ in the affected eye and 20/25 in the opposite eye. No afferent pupillary defect was identified. Visual fields could not be assessed due to poor vision. Fundus examination was normal bilaterally. The patient first noticed the proptosis in 2015 (6 years ago) for which he sought medical attention then lost follow-up. Since then, the lesion had been slowly growing but especially worsening over the past year. No significant medical or surgical history was noted.

\section{INVESTIGATIONS}

The patient first presented at another hospital in 2015 and had a CT scan of the orbit there with no further details available to us. A biopsy was attempted at the time which turned out to be uninformative, yielding non-representative benign lacrimal tissue only. The patient lost follow-up for 6 years, during which the mass was gradually increasing in size. He eventually sought medical attention at our specialised eye centre due to worsening proptosis and decreased vision over the past year. Recent MRI revealed an extraconical anterolateral $3.8 \times 3.5 \times 2.0 \mathrm{~cm}$ solid-cystic mass in the right orbit, showing a heterogeneous intensity and marked contrast enhancement, most likely originating from the lacrimal gland, which appeared inseparable from it (figure 1B,C). The mass abutted the lateral aspect of the eye globe and lateral rectus muscle, resulting in globe displacement and 

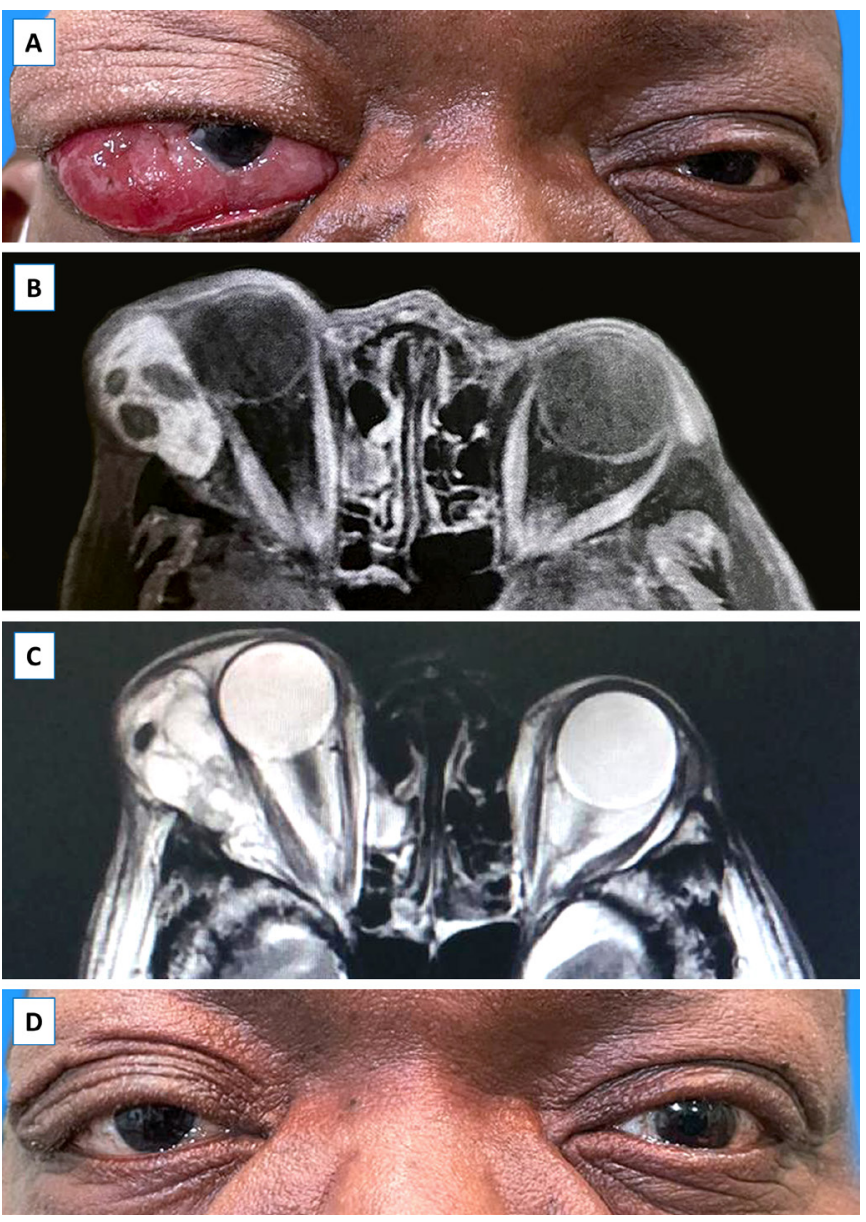

Figure 1 (A) Preoperative photograph showing right proptosis and a protruding tumour; $(\mathrm{B}, \mathrm{C}) \mathrm{MRI}$ orbit, $\mathrm{T} 1$ and $\mathrm{T} 2$, respectively, showing a markedly enhancing solid and cystic lesion abutting the globe and medial rectus muscle; (D) 3 months postoperatively.

proptosis without evidence of ocular or muscular infiltration. No bone erosion or marrow oedema seen.

\section{DIFFERENTIAL DIAGNOSIS}

In view of the longstanding clinical history and imaging characteristics, particularly the circumscribed non-infiltrative nature of the lesion, a benign/indolent neoplasm was favoured clinically, although malignancy could not be totally excluded. Localising the mass to the extraconical compartment, specifically to the lacrimal gland, further helped narrow down the list of differentials, which included epithelial and non-epithelial neoplasms as well as non-neoplastic mimics. Pleomorphic adenoma, an epithelial neoplasm and the most common benign neoplasm of the lacrimal gland, was on top of the list. Malignant epithelial lesions, on the other hand, were less likely (of which adenoid cystic carcinoma is the most common). A cavernous vascular malformation was also entertained; however, the extraconal location of the mass was atypical for this diagnosis. ${ }^{8}$ Lymphoma of the lacrimal gland, such as mucosa-associated lymphoid tissue-type (lymphoma), was at the bottom of the list especially in the absence of extraorbital systemic disease. Finally, a metastatic tumour could not be ruled out. Non-neoplastic conditions of the lacrimal gland (such as sarcoidosis) may mimic neoplasia and were also entertained. SFT was not considered at this point. Eventually, histopathological evaluation was needed to establish a definite tissue diagnosis.
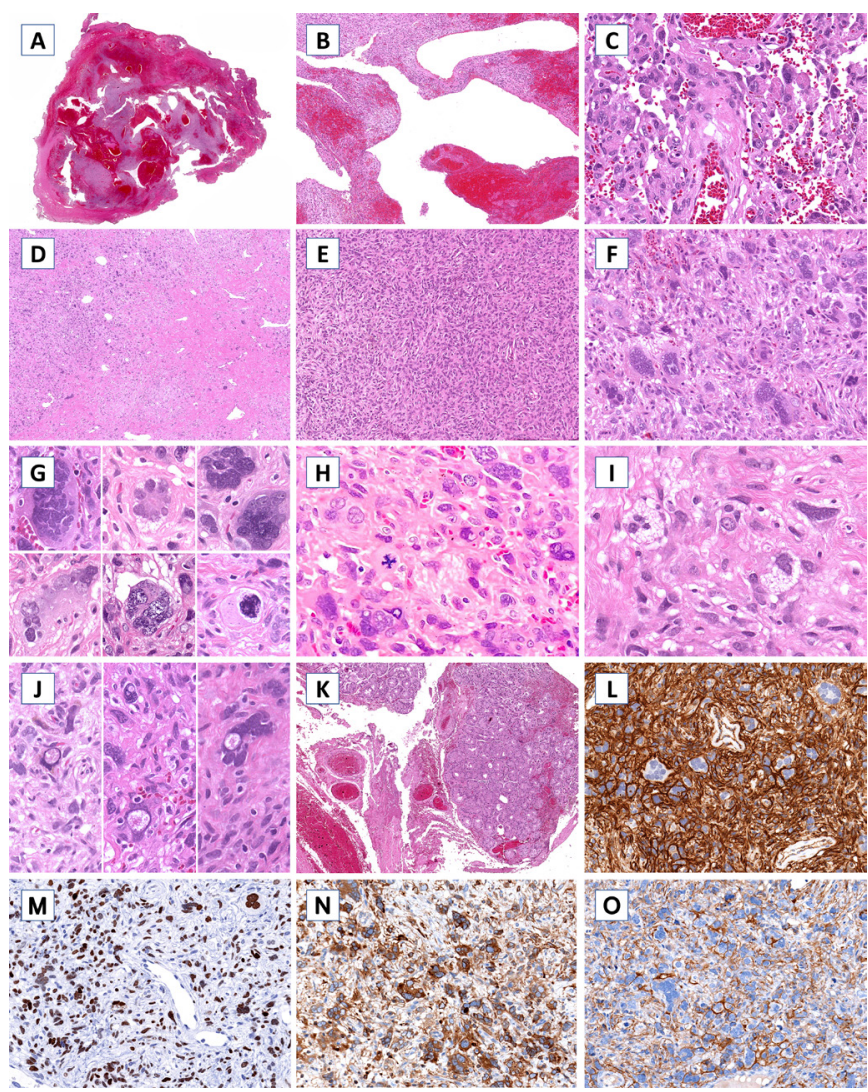

Figure 2 (A) Low magnification view shows cystic/angiomatoid appearance of the tumour $(H \& E, \times 0.4)$. (B) Pseudovascular cystic spaces $(H \& E, \times 1.5)$. (C) Small capillary-sized vessels and sinusoid-like spaces $(H \& E, \times 20)$. (D) Alternating sclerosing and cellular areas with staghorn-like vessels $(H \& E, \times 4)$. (E) Storiform pattern $(H \& E, \times 10)$; (F) Spindled cells and multinucleated giant cells $(H \& E, \times 20)$. (G) Types of multinucleated giant cells with and without nuclear atypia $(\mathrm{H} \& \mathrm{E}$, $\times 40)$. (H) Atypical mitotic figure $(H \& E, \times 40)$. (I) Cells with vacuolated cytoplasm $(H \& E, \times 40)$. (J) Intranuclear inclusions $(H \& E, \times 40)$.

(K) Residual lacrimal gland tissue at the periphery of the tumour (H\&E, $\times 10)$. (L-0) CD34, STAT6, BCL2 and CD99 immunohistochemical stains, respectively $(H \& E, \times 20)$.

\section{TREATMENT}

The patient underwent surgery under general anaesthesia via upper lid crease anterolateral orbitotomy approach (figure 1D). The procedure proved to be challenging due to intraoperative haemorrhage and adherence of the mass to surrounding structures. Presurgical embolisation was not employed as this was not anticipated. The hypervascularity and bleeding precluded complete removal of the tumour so a subtotal resection was performed instead. At this point, a vascular tumour/malformation was highly suspected clinically. The specimen was sent to histopathology.

On gross pathological examination, the mass measured $3.5 \times 2.0 \times 2.0 \mathrm{~cm}$ and its cut surface revealed blood-filled cystic spaces as well as solid areas. Histologically, the tumour showed a prominent angiomatoid appearance in the form of large bloodfilled cytic spaces, small capillary-sized vessels and sinusoid-like spaces (figure $2 \mathrm{~A}-\mathrm{C}$ ). At first glance, the striking vascularity was alarming for angiosarcoma mandating immunohistochemical evaluation. On closer inspection of the solid tumour component, a 'patternless' pattern with alternating hypocellular and hypercellular areas was appreciated along with staghorn-like vessels 
(figure 2D) and a focal storiform architecture (figure 2E). A dual population of cells were apparent: spindled fibroblast-like cells and large multinucleated giant cells (figure 2F), the latter of which showed nuclei nested in the centre of the cell or at the periphery (floret-like or Touton giant cell-like cells) (figure 2G). Some nuclei appeared smudged and degenerative, while others were markedly atypical (figure 2G). However, mitotic activity was disproportionately low (up to $3 / 10 \mathrm{hpf}$ ). After a meticulous search, an occasional atypical mitotic form was identified (figure $2 \mathrm{H}$ ). Occasional cells had vacuolated cytoplasm superficially resembling lipoblasts (figure 2I). ${ }^{3}$ Conspicuous intranuclear pseudoinclusions were seen (figure $2 \mathrm{~J}$ ). ${ }^{6}$ Residual lacrimal glandular elements were identified at the periphery of the tumour (figure $2 \mathrm{~K}$ ). Other than angiosarcoma, sarcomatoid carcinoma and undifferentiated pleomorphic sarcoma were also considered. On immunohistochemistry, tumour cells were negative for epithelial, melanocytic, neural, muscular and vascular endothelial markers (CD31 and factor VIII) but were diffusely positive for CD34 (figure 2L). STAT6 showed intense nuclear staining in the mononucleated and multinucleated cells reflective of an underlying NAB2-STAT6 fusion (figure 2M). ${ }^{7}$ BCL2 and CD99 were also positive (figure $2 \mathrm{~N}, \mathrm{O}$ ). Ki-67 proliferative index was low. This picture was consistent with a GCR-SFT.

Molecular testing confirmed the presence of a fusion variant NAB2e $\times 3$-STAT6e $\times 18$ (using targeted RNA fusion sequencing). Additionally, a TP53 mutation (c. 437_440delGGGT, p. W146fs) was identified. ${ }^{39}$

\section{OUTCOME AND FOLLOW-UP}

Postoperatively, the patient experienced complete remission of the proptosis down to $21 \mathrm{~cm}$ with resolution of the conjunctival and corneal changes. Visual acuity was significantly improved at 20/25. Extraocular movements showed full ocular motility with minimal restriction in adduction. After 3 months of follow-up, there was no obvious regrowth of the mass on physical examination; however, the clinical outlook remains guarded in view of the incomplete resection. The patient was referred to an oncologist for further management and for a follow-up MRI to monitor the residual disease.

\section{DISCUSSION}

Orbital SFT is an uncommon mesenchymal neoplasm that is increasingly being recognised and reported mostly due to improved diagnostics and histological criteria. In the most comprehensive review of the English literature to date, ${ }^{10} 263$ orbital SFTs have been identified between 1966 and 2019. SFT comprises a spectrum with diverse histological features encompassing GCR-SFT, which is a rare variant with a predilection for the orbital region, characterised histologically by a spindle-cell proliferation, pseudovascular spaces and multinucleate floretlike giant cells. ${ }^{11-13}$

Although orbital SFTs are richly vascularised, extensive cystic change is unusual and may pose a diagnostic difficulty. ${ }^{14-19}$ Rare entirely cystic examples may lead to confusion with other entities such as vascular tumours or even a hydatid cyst in one report. ${ }^{121518}$ Another report described three recurrent orbital SFTs containing cysts filled with mucoid material leading the authors to suggest that cystic degeneration may be associated with locally aggressive behaviour. ${ }^{17}$ In our case, the cystic nature was due to blood-filled pseudovascular spaces leading to an erroneous initial impression of a vascular neoplasm. Such appearance may be particularly challenging for general radiologists/ophthalmologists/pathologists who are not exposed to ophthalmic oncology cases on a regular basis.

SFTs characteristically harbour inv12(q13q13)-derived NAB2-STAT6 fusions with variable breakpoints resulting in diverse fusion variants that seem to correlate with some clinicopathological features particularly anatomic location of the tumour. ${ }^{2021}$ SFTs in the head and neck, however, have shown more genetic heterogeneity in the NAB2-STAT6 variants with one study demonstrating a NAB2e $\times 6$-STAT6e $\times 17$ variant in 3 out of 5 orbital GCR-SFT cases. ${ }^{7}$ In our case, a rare NAB2e $\times 3$ STAT6e $\times 18$ fusion variant was detected, which was previously reported in a large SFT in the brain of a 75 -year-old patient who had no disease progression 3 years after surgery. ${ }^{22}$ Nonetheless, the significance of such fusion variants in the orbit remains to be seen. Additionally, our case showed a TP53 mutation on targeted next-generation sequencing. TP53 mutations have been associated with aggressive behaviour and dedifferentiation in SFT. ${ }^{21}$ Our patient had the tumour for at least 6 years without demonstrating aggressive behaviour, such as local infiltration into adjacent structures, but he did report a recent increase in size over the past 1 year which may be related to the acquisition of additional mutations including that of TP53. TERT promoter mutation, another adverse factor, was not detected in this case. ${ }^{21}$

Predicting the clinical course of SFTs is an enigma since histology is not usually predictive of biological behaviour. This is particularly true of orbital SFTs which are inadequately studied due to their rarity. Several risk-assessment models exist for predicting local recurrences and/or distant metastasis in SFTs irrespective of their site. ${ }^{2324}$ Recently, Thompson et al proposed a site-specific model unique to orbital SFTs incorporating age, tumour size, tumour necrosis, mitoses, cellularity, and pleomorphism. ${ }^{10}$ Such models, however, may not be fully applicable to our case since the patient is known to have residual disease due to incomplete surgical excision making tumour regrowth inevitable. Our case would have been regarded as 'intermediate risk' based on the Thompson model with a total score of 4: 0 for patient age at initial presentation ( $\leq 45$ years old), 2 for tumour size $(>3 \mathrm{~cm}), 0$ for mitotic activity $\left(\leq 4\right.$ mitoses $\left./ 2 \mathrm{~mm}^{2}\right), 1$ for cellularity (moderate to high), 1 for pleomorphism (moderate to high) and 0 for necrosis (absent). ${ }^{10}$ Despite the cellular pleomorphism in this case, mitotic activity was disproportionately low.

Complete surgical removal of orbital SFT is the mainstay of treatment, sometimes preceded by preoperative embolisation in order to reduce the risk of intraoperative bleeding as recommended by several papers. ${ }^{25}{ }^{26}$ Angiography may be used preoperatively to assess the tumour vascularity and to better plan for the surgery. Incomplete resection of SFT is a risk factor for local recurrences and/or malignant transformation along with the potential to metastasise sometimes many years later. Some incompletely excised cases may benefit from adjuvant radiotherapy or chemotherapy.

\section{Learning points}

- Giant cell-rich solitary fibrous tumour should be considered in the differential diagnosis of a cystic orbital lesion.

- Extensive angiomatoid change in orbital SFT may mimic a vascular neoplasm.

- Complete surgical excision may be hindered by profuse bleeding necessitating preoperative embolisation.

- Orbital solitary fibrous tumours harbour heterogenous NAB2STAT6 fusion variants. 
Twitter Karen Pinto @thekarenpinto and Rola H Ali @DrRolaAli

Acknowledgements We thank Dr Tahani Baqer (pathologist, Kuwait Cancer Control Center) for contributing the case. We also thank Ms Mona Alateegi (molecular technologist, Kuwait Cancer Control Center) for her technical assistance, and Dr. Shakir Bahzad (molecular pathologist, Kuwait Cancer Control Center) for the interpretation of the molecular result.

Contributors KAA and MA were responsible for managing the patient, obtaining clinical data and editing the manuscript. KP was responsible for obtaining pathology data and editing the manuscript. RHA was responsible for collection of data, preparation of figures, reviewing the literature, and writing the manuscript.

Funding The authors have not declared a specific grant for this research from any funding agency in the public, commercial or not-for-profit sectors.

Competing interests None declared.

Patient consent for publication Consent was obtained directly from patient(s). Provenance and peer review Not commissioned; externally peer reviewed.

Open access This is an open access article distributed in accordance with the Creative Commons Attribution Non Commercial (CC BY-NC 4.0) license, which permits others to distribute, remix, adapt, build upon this work non-commercially, and license their derivative works on different terms, provided the original work is properly cited and the use is non-commercial. See: http://creativecommons.org/ licenses/by-nc/4.0/.

Case reports provide a valuable learning resource for the scientific community and can indicate areas of interest for future research. They should not be used in isolation to guide treatment choices or public health policy.

\section{ORCID iD}

Rola H Ali http://orcid.org/0000-0001-5747-8900

\section{REFERENCES}

1 Westra WH, Gerald WL, Rosai J. Solitary fibrous tumor. consistent CD34 immunoreactivity and occurrence in the orbit. Am I Surg Pathol 1994;18:992-8.

2 Dorfman DM, To K, Dickersin GR, et al. Solitary fibrous tumor of the orbit. Am J Surg Pathol 1994;18:281-7.

3 Furusato E, Valenzuela IA, Fanburg-Smith JC, et al. Orbital solitary fibrous tumor: encompassing terminology for hemangiopericytoma, giant cell angiofibroma, and fibrous histiocytoma of the orbit: reappraisal of 41 cases. Hum Pathol 2011;42:120-8.

4 Schweizer L, Koelsche C, Sahm F, et al. Meningeal hemangiopericytoma and solitary fibrous tumors carry the NAB2-STAT6 fusion and can be diagnosed by nuclear expression of STAT6 protein. Acta Neuropathol 2013;125:651-8.

5 Dei Tos AP, Seregard S, Calonje E, et al. Giant cell angiofibroma. A distinctive orbital tumor in adults. Am J Surg Pathol 1995:19:1286-93.

6 Guillou L, Gebhard S, Coindre JM. Orbital and extraorbital giant cell angiofibroma: a giant cell-rich variant of solitary fibrous tumor? clinicopathologic and immunohistochemical analysis of a series in favor of a unifying concept. Am J Surg Pathol 2000;24:971-9.

7 Kao Y-C, Lin P-C, Yen S-L, et al. Clinicopathological and genetic heterogeneity of the head and neck solitary fibrous tumours: a comparative histological, immunohistochemical and molecular study of 36 cases. Histopathology 2016;68:492-501.

8 Tailor TD, Gupta D, Dalley RW, et al. Orbital neoplasms in adults: clinical, radiologic, and pathologic review. Radiographics 2013;33:1739-58.

9 Park HK, Yu DB, Sung M, et al. Molecular changes in solitary fibrous tumor progression. J Mol Med 2019;97:1413-25.

10 Thompson LDR, Liou SS, Feldman KA. Orbit solitary fibrous tumor: a proposed risk prediction model based on a case series and comprehensive literature review. Head Neck Pathol 2021;15:138-52.

11 Son $\mathrm{DH}$, Yoo SH, Sa H-S, et al. A solitary fibrous tumor with giant cells in the lacrimal gland: a case study. Korean J Pathol 2013;47:158-62.

12 Demirci H, Shields CL, Eagle RC, et al. Giant cell angiofibroma, a variant of solitary fibrous tumor, of the orbit in a 16-year-old girl. Ophthalmic Plast Reconstr Surg 2009;25:402-4.

13 Ereño C, López Jl, Pérez J. Orbital giant cell angiofibroma. Report of a recurrent case. APMIS 2006;114:663-5.

14 Krishnakumar S, Subramanian N, Mohan ER, et al. Solitary fibrous tumor of the orbit: a clinicopathologic study of six cases with review of the literature. Surv Ophthalmol 2003;48:544-54.

15 Feuerman JM, Flint A, Elner VM. Cystic solitary fibrous tumor of the orbit. Arch Ophthalmol 2010;128:385-7.

16 Polomsky M, Sines DT, Dutton JJ. Solitary fibrous tumor of the orbit with multiple cavities. Ophthalmic Plast Reconstr Surg 2013;29:e117-9.

17 Graue GF, Schubert HD, Kazim M. Correlation between clinical features, imaging and pathologic findings in recurrent solitary fibrous tumor of the orbit. Orbit 2013;32:375-80.

18 Alam S, Backiavathy V, Mukherjee B, et al. A rare case of giant multicystic solitary fibrous tumor of the orbit. Orbit 2018;37:69-72.

19 Gheorghisan-Galateanu A-A, Terzea DC, Burcea I, et al. Cystic appearance - a new feature of solid fibrous tumours in the lacrimal gland: a case report with literature review. Diagn Pathol 2019;14:63.

20 Tai H-C, Chuang I-C, Chen T-C, et al. Nab2-Stat6 fusion types account for clinicopathological variations in solitary fibrous tumors. Mod Pathol 2015;28:1324-35.

21 Akaike K, Kurisaki-Arakawa A, Hara K, et al. Distinct clinicopathological features of NAB2-STAT6 fusion gene variants in solitary fibrous tumor with emphasis on the acquisition of highly malignant potential. Hum Pathol 2015;46:347-56.

22 Guseva NV, Tanas MR, Stence AA, et al. The NAB2-STAT6 gene fusion in solitary fibrous tumor can be reliably detected by anchored multiplexed PCR for targeted next-generation sequencing. Cancer Genet 2016;209:303-12.

23 Salas S, Resseguier N, Blay JY, et al. Prediction of local and metastatic recurrence in solitary fibrous tumor: construction of a risk calculator in a multicenter cohort from the French sarcoma group (FSG) database. Ann Oncol 2017;28:1779-87.

24 Demicco EG, Wagner MJ, Maki RG, et al. Risk assessment in solitary fibrous tumors: validation and refinement of a risk stratification model. Mod Pathol 2017;30:1433-42.

25 Vijitha VS, Kapoor AG, Mittal R, et al. Preoperative embolisation of orbital solitary fibrous tumour. BMJ Case Rep 2020;13:e235576.

26 Wang $X$, Shen J, Cui H, et al. Preoperative transarterial embolization of a recurrent orbital solitary fibrous tumor with significant hypervascularity: a case report. $B M C$ Surg 2021;21:92.

Copyright 2022 BMJ Publishing Group. All rights reserved. For permission to reuse any of this content visit https://www.bmj.com/company/products-services/rights-and-licensing/permissions/ BMJ Case Report Fellows may re-use this article for personal use and teaching without any further permission.

Become a Fellow of BMJ Case Reports today and you can:

- Submit as many cases as you like

- Enjoy fast sympathetic peer review and rapid publication of accepted articles

- Access all the published articles

Re-use any of the published material for personal use and teaching without further permission

Customer Service

If you have any further queries about your subscription, please contact our customer services team on +44 (0) 2071111105 or via email at support@bmj.com.

Visit casereports.bmj.com for more articles like this and to become a Fellow 